\title{
The effect of maternal body mass index on duration of induced labor
}

Sara Carlhäll, Karin Kallen and Marie Blomberg

The self-archived postprint version of this journal article is available at Linköping University Institutional Repository (DiVA):

http://urn.kb.se/resolve?urn=urn:nbn:se:liu:diva-163623.

N.B.: When citing this work, cite the original publication.

Carlhäll, S., Kallen, K., Blomberg, M., (2020), The effect of maternal body mass index on duration of induced labor, Acta Obstetricia et Gynecologica Scandinavica. https://doi.org/10.1111/aogs.13795

Original publication available at:

https://doi.org/10.1111/aogs.13795

Copyright: Wiley (12 months)

http://eu.wiley.com/WileyCDA/ 
Title page

Title: The effect of maternal body mass index on duration of induced labor.

List of authors:

Sara Carlhäll MD, $\mathrm{PhD}^{1}$, Karin Källén Prof ${ }^{2}$ and Marie Blomberg MD, Prof ${ }^{1}$.

${ }^{1}$ Department of Obstetrics and Gynecology and Department of Clinical and Experimental Medicine, Linköping University, 58185 Linköping, Sweden.

${ }^{2}$ Institution of Clinical Sciences Lund, Center for Reproductive Epidemiology, Tornblad Institute, Lund University, 22632 Lund, Sweden.

Corresponding author:

Sara Carlhäll, $\mathrm{MD}, \mathrm{PhD}$

Department of Obstetrics and Gynecology and Department of Clinical and Experimental Medicine, Linköping University, 58185 Linköping, Sweden

Tel: 0046101030000

E-mail address: sara.carlhall@,regionostergotland.se

Conflicts of interest statement: The authors declare no conflicts of interest.

Funding information: This study was supported by ALF-grants Region Östergötland Sweden. 


\begin{abstract}
Introduction: Obese primiparae women with induction of labor are at high risk for a cesarean section (CS). There are contradictory results regarding time in induced labor in relation to maternal body mass index (BMI). It is important to characterize the course of induced labor in order to prevent unnecessary CS. We aimed to evaluate whether the duration of labor was associated with maternal BMI in primiparae women with induction of labor.
\end{abstract}

Material and methods: A national retrospective cohort study, including 15259 primiparae women with a single term pregnancy, admitted for induction of labor from January 2014 to August 2017. Data were obtained from the Swedish Pregnancy Registry. Cox regression analyses were used to illustrate the association between BMI and active labor and between BMI and time from admission until start of active labor.

Results: Duration of active labor was shorter in underweight women and prolonged in women with BMI $\geq 40$ compared to women in other BMI classes, illustrated by cox regression graphs $(\mathrm{p}<0.001)$. The median duration of active labor in underweight women were 6.1 hours and 7.4 hours in women with BMI $\geq 40$. The time from admission until start of active labor increased with maternal BMI, illustrated by cox regression graphs $(p<0.001)$ and the median duration increased from 12.9 hours in underweight women to 22.6 hours in women with $\mathrm{BMI} \geq 40$. The CS rate in active labor increased significantly with BMI $(\mathrm{p}<0.001)$ from $7.4 \%$ in underweight women to $22.0 \%$ in women with $\mathrm{BMI} \geq 40$. Obese and normal weight women had similar rates of spontaneous vaginal delivery $(69.9 \%$ in the total studypopulation).

Conclusions: The duration of active labor was associated with maternal BMI for underweight women and women with $\mathrm{BMI} \geq 40$. Although women with $\mathrm{BMI} \geq 40$ who reached the active phase of labor had the same chance for a spontaneous vaginal delivery as normal weight women, the duration of active labor and the CS rate were increased. The time from admission until start of active labor increased successively with maternal BMI.

Key words: induction of labor, duration of labor, obesity, active phase of labor, cesarean section
Abbreviations: $\mathrm{BMI}=$ body mass index, $\mathrm{IOL}=$ induction of labor, $\mathrm{CS}=$ cesarean section, $\mathrm{PE}=$ preeclampsia, $\mathrm{GDM}=$ gestational diabetes mellitus, $\mathrm{GWG}=$ gestational weight gain

Key message: Obese women with induction of labor spend longer time from admission until start of active labor than normal-weight women. Women with $\mathrm{BMI} \geq 40$ had longer active 
labor than women in other BMI-classes but the same chance for a spontaneous vaginal delivery.

\section{INTRODUCTION}

The increasing prevalence of overweight and obesity in pregnant women is worrying, considering the associated obstetrical interventions and complications. ${ }^{1,2}$ Obese women are more likely to undergo induction of labor (IOL) compared to normal weight women. ${ }^{3-5}$ This is partly explained by the positive association between maternal obesity and post-term pregnancy. ${ }^{6-8}$ The increased rate of pregnancy complications, such as pre-eclampsia (PE), hypertension, intrauterine fetal death and diabetes mellitus in obese women also contributes to the greater need for IOL. ${ }^{2}$ IOL is a common intervention in contemporary obstetrical practice. In $2016,17.2 \%$ of all primiparae women in Sweden were induced. ${ }^{9}$ Studies have reported higher rates of cesarean section (CS) in primiparae women following IOL, compared to women with a spontaneous onset of labor ${ }^{10,11}$ and the risk of a CS increases with maternal weight. ${ }^{3-5,12}$ Considering the increasing prevalence of obesity and associated risk for a CS, obese primiparae women with IOL represent a challenging risk group in contemporary obstetrical care. One of the most common reasons for failed IOL in obese women is failure to progress. ${ }^{13,14}$ We have previously shown that time in spontaneous labor increases with maternal body mass index (BMI) ${ }^{15}$ and various authors have suggested that obese women might need more time in active labor before the arrest of labor can be considered. ${ }^{16}$

If a prolonged active induced labor is associated with maternal BMI in the same way as in women with spontaneous labor this may contribute to the higher rates of CS in obese primiparae women. The results from several studies indicate that total time in induced labor increases with maternal weight. ${ }^{12,17,18}$ However, there are contradictory results regarding time in the active induced labor in relation to maternal BMI. ${ }^{17,19,20}$ It is important to characterize the course of induced labor in order to prevent unnecessary CS due to labor arrest in primiparae women for whom a CS may have a major impact on future pregnancies and deliveries.

Hence, our primary aim was to evaluate whether the time in active labor was associated with BMI in primiparae women with induced labor. The secondary aim was to analyze the duration of time from admission until start of active labor in relation to maternal BMI.

\section{MATERIAL AND METHODS}


We performed a national retrospective cohort study, including 15259 primiparae women with a single term ( $\geq 37$ gestational weeks) pregnancy. The women were admitted to a delivery ward in Sweden for IOL and delivered between January 1, 2014 and August 30, 2017. Data were obtained from the Swedish Pregnancy Register. The register contains information on maternal characteristics, pregnancy complications, and labor and birth data from $90 \%$ of all deliveries in Sweden. The majority of the variables included in the register are continuously transferred electronically from the medical antenatal, labor and delivery records. Some variables are registered manually by the midwives at the antenatal care clinics. These data include country of birth, level of education and diagnosis of gestational diabetes mellitus (GDM).

Exclusion criteria were stillbirth, non-available information on maternal BMI in the first trimester, no information on maternal age, and missing data concerning time estimates on the start of active labor and the time of birth. Thus, the women who had a CS before onset of active labor were excluded, but the women who were delivered by CS in active labor were included in the analyses on labor duration.

Maternal BMI was calculated based upon the maternal weight and height measurements provided at the first antenatal visit in gestational week eight to ten. The study population was categorized in six classes of BMI $\left(\mathrm{kg} / \mathrm{m}^{2}\right)$ according to the World Health Organization (WHO) definition: $<18.5 \mathrm{~kg} / \mathrm{m}^{2}$ (underweight), $18.5-24.9 \mathrm{~kg} / \mathrm{m}^{2}$ (normal weight), 25.0-29.9

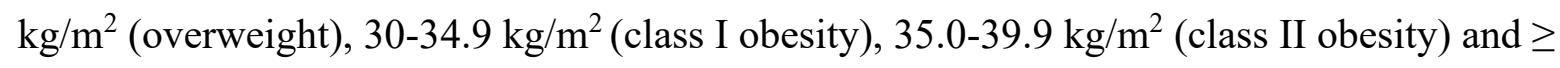
$40 \mathrm{~kg} / \mathrm{m}^{2}$ (class III obesity/morbidly obese).

After the application to the register holders was approved, data from the Swedish Pregnancy Register was retrieved unidentified. The maternal variables that were assessed were age at delivery, height and weight in the first trimester, weight in late pregnancy, smoking in early pregnancy, educational level, country of birth, pre-pregnancy diabetes and hypertension, GDM, PE and gestational age at delivery. Labor and neonatal variables that were assessed were type of labor (spontaneous, induction or planned CS), the time at admission for IOL, the time of start of active labor, the time of birth, usage of epidural anesthesia, usage of oxytocin, mode of delivery (spontaneous vaginal delivery, operative vaginal delivery and emergency $\mathrm{CS}$ ), whether or not the infant was borne alive and birthweight.

Maternal age was defined as completed years at time of delivery. Gestational weight gain (GWG) was defined as the difference between the maternal weight in early pregnancy and the last weight measured in the third trimester, (on average obtained at 36.3 weeks). GDM was 
defined as fasting plasma glucose value $\geq 7.0 \mathrm{mmol} / 1$ or $\geq 10.0 \mathrm{mmmol} / 1$ as the 2-hour value after an oral glucose tolerance test. Gestational age was based on the measurements from a second trimester ultrasound. Onset of the active phase labor was defined as when the cervix was dilated $3 \mathrm{~cm}$ or more in women with painful regular uterine contractions. This definition was based on a state-of-the-art document by the Swedish National Board of Health and Welfare published in 2001. The midwife at the delivery ward prospectively recorded the time when the active phase of labor started and the time of birth. Emergency CS was defined as a CS performed after the start of IOL, during active labor.

Duration of labor was defined and analyzed in two different ways. First, as time in active labor, defined as from the start of the active phase of labor until time of birth. Second, as the time from admission to the delivery ward for IOL until the start of the active phase of labor, since the exact time for start of induction was not available in the Swedish Pregnancy Register. This includes the time to prepare the start of induction, to decide induction method and the time for cervical ripening, if required. The time estimates were considered to be incorrect if the time from admission until active labor started was less than 30 minutes or more than four days (96 hours). We assumed that some values could have been misrecorded before start of IOL. We therefore estimated that the maximum duration of time from admission until active labor would be the total maximum duration of all induction methods together; prostaglandines for 48 hours, ballon catheter for 24 hours and oxytocin infusion (including a possible pause and a second try) for 24 hours. If all methods are used in one patient the maximum time duration would be 96 hours.

\section{Statistical analyses}

$\mathrm{Chi}^{2}$-tests were performed to analyze descriptive frequency data, while one-way analyses of variance (ANOVA) were conducted to compare descriptive, continuous, and normally distributed data among BMI groups. The relation between BMI and CS was evaluated by using a linear logistic regression model with BMI as a linear, continuous variable.

One-way ANOVAs were used to compare mean duration of active labor and mean time from admission until active labor, respectively, among BMI groups. When the outcome variables were not normally distributed, the log values were used instead (provided that they seemed to be reasonably normally distributed). Analyses of covariance (ANCOVA) were used to control for possible confounders. Only factors with $\mathrm{p}<0.2$ were included in the final analyses. In the final analyses, adjustments were made for maternal age, GWG, and birthweight. The analyses on active labor were also adjusted for vaginal delivery. 
Cox regression analyses were performed and graphs were produced to illustrate the association between maternal BMI and time in active labor and time from admission until active labor in women with IOL, taking censoring due to emergency CS into account (when applicable) and adjusting for confounding factors. Cox regression analyses were used to assess the contributions of variables identified as single independent factors influencing time in active labor and time from admission until active labor started $(\mathrm{p}<0.2)$. Maternal age, infant birthweight, smoking in first trimester, and GWG were included as confounding factors in the analyses on active labor. Birthweight and GWG were regarded as confounding factors in the analyses on time from admission until active labor.

A p-value $<0.05$ was considered statistically significant. Statistical analyses were performed using IBM SPSS version 23 (IBM Inc, Armonk, NY).

\section{Ethical approval}

The Regional Ethical Review Board in Linköping, Sweden approved this study (Dnr 2017/274-31).

\section{RESULTS}

During the study period between January 1, 2014 and August 30, 2017, 140452 primiparae women delivered a singleton term pregnancy, and had their data available in the Swedish Pregnancy Register. The induction rate was 19.9\% (27 896 women). 15259 women with induced labor, information on start of active labor and time of birth were included in the analyses on active labor. Out of these women, 15073 were included in the analyses of the time from admission until start of active labor (Figure 1).

The maternal demographics are listed in Table 1. Morbidly obese women were more likely to be of Nordic origin (born in Sweden or Nordic countries), to smoke in first trimester, and to have a lower education level compared to normal weight women ( $p$ for homogeneity $<0.001$ ). The incidence of GDM or PE was not significantly different over the BMI categories. The higher the BMI class, the less the GWG (p for homogeneity $<0.001$ ).

Labor characteristics are presented in Table 2. Mean birthweight was higher with increasing maternal BMI. A gestational age at delivery of $\geq 42$ weeks was more common in normal weight women than among obese women ( $\mathrm{p}$ for homogeneity $<0.001$ ). An operative vaginal delivery was less common with higher maternal BMI: $15.6 \%$ in normal weight women compared to $6.1 \%$ in morbidly obese women ( $\mathrm{p}$ for homogeneity $<0.001$ ). The rate of emergency CS increased significantly with increasing BMI class, from $7.4 \%$ in underweight 
women to $22.0 \%$ in morbidly obese women ( $\mathrm{p}$ for linear trend $<0.001$ ). Obese women had the same chance for a spontaneous vaginal delivery as normal weight women after IOL. The reported usage of oxytocin did not differ substantially among the BMI classes, except for underweight women.

The medians, quartiles and range values of time in labor by BMI category are presented in Table 3. Underweight women had 0.9-1.5 hours shorter duration of median active labor compared to women in the other BMI categories. The median time from admission until active labor increased successively with maternal BMI from 12.9 hours in underweight women to 22.6 hours in morbidly obese women.

The values of the durations of active labor and the time from admission until active labor were not normally distributed $(\mathrm{p}<0.001)$. Instead, the logarithmic values were used to explore differences between BMI classes using ANOVA and ANCOVA. One-way ANOVAs revealed significant heterogeneity between BMI classes, both for log active labor and log "time admission to active labor" durations $(\mathrm{p}<0.001)$. When ANCOVAs were performed including maternal age, GWG, birthweight and vaginal delivery as confounders, significant differences between BMI classes were still found for both outcomes (log duration of active labor, $p=0.02$, and log "time admission to active labor" duration, $\mathrm{p}<0.001)$.

The relation between maternal BMI and the duration of active labor and the time from admission until start of active labor is presented as graphs from cox regression analyses, in figures 2 and 3. Figure 2 illustrates the duration of active labor by BMI category taking censoring from emergency CS into account and adjusting for confounding factors, hence, all women with CS during the active labor were included in these analyses. The figure shows that the number of women who were still in active labor at a certain time point were less in underweight women $(\mathrm{BMI}<18.5)$ and increased in morbidly obese women (BMI $>40)$, compared to women in other BMI categories. Cox regression analyses were used to assess the contributions of variables identified as single independent factors influencing time in active labor and the time from admission until start of active labor $(p<0.2)$. The overall difference between the curves was statistically significant when adjusting for maternal age, infant birthweight, smoking in first trimester and GWG as confounding factors $(\mathrm{p}<0.001)$. The relation between the time from admission until start of active labor and maternal BMI is presented in figure 3. Time from admission until active labor increased successively with increasing maternal BMI class (figure 3). There was an overall statistically significant difference between the curves when adjusting for birthweight and GWG $(p<0.001)$. 


\section{DISCUSSION}

This is one of the largest population-based cohort studies restricted to primiparae women with induced labor and information on early pregnancy BMI. Graphs from cox regression analyses demonstrated that the duration of active labor was shorter in underweight women and prolonged in women with $\mathrm{BMI} \geq 40$ compared to women in other BMI classes, who had almost similar duration of active labor. Our results indicate that maternal BMI seems to have a greater impact on time from admission until start of active labor which increased successively with increasing maternal BMI.

There are several previous studies comparing labor progress by maternal weight but few studies have been restricted to women with IOL and few have analyzed the from admission until start of active labor and active labor separately. ${ }^{12,17-20}$ Three American studies, including both spontaneous and induced labor, demonstrated that the time from 4 to $10 \mathrm{~cm}$ cervical dilatation increased with maternal BMI in primiparae women. ${ }^{16,21,22}$ Contradictory results were reported in a Danish study on 1885 primiparae women. ${ }^{23}$ In women with IOL, increasing maternal weight has been associated with longer time from start of induction to delivery. However, the results may be less generalizable as they are based on maternal weight at the time of induction. ${ }^{12,17,18}$ One of these studies also demonstrated that time in active labor, from $4 \mathrm{~cm}$ cervical dilatation, increased with maternal BMI. ${ }^{17}$ Hirshberg et al. compared the latent and the active phases in 313 primiparae women undergoing IOL by BMI category. In contrast to our findings they found no difference in median time from start of induction until active labor by BMI category, but a significantly longer median time in active labor from five cm cervical dilatation, in overweight women compared to normal weight and obese women. However, due to different definitions of start of active labor and size of the study-population, our results are not comparable. ${ }^{19}$ In two separate studies on women undergoing IOL, the duration of active labor was similar, regardless of maternal BMI. As they mixed parities in the analyses and defined the start of active labor differently or not at all, our results are difficult to adequately compare. ${ }^{3,20}$

The current analysis supports previous findings that the CS rate increased with rising maternal BMI in primiparae women undergoing IOL. ${ }^{3,4,12}$ Furthermore, this study showed that induced overweight and obese women who enter the active stage of labor have the same chance for a spontaneous vaginal delivery as normal weight women. In this large study population, $70 \%$ had spontaneous vaginal delivery. This finding is different to a British study 
on 2066 primiparae women with IOL where $44 \%$ had a spontaneous vaginal delivery and fewer obese women had a spontaneous vaginal delivery compared to normal weight women. ${ }^{3}$ Although there was no difference between normal weight, overweight and women with obesity class I-II regarding time in active labor, and that all had the same chance for a spontaneous vaginal delivery, the rate of CS increased noticeably, with increasing BMI. The reason for this can only be speculated upon. Since the risk of an operative vaginal delivery decreases with maternal BMI, it is possible that more obese women are delivered by CS during the first stage of labor. ${ }^{17,245}$ It may also reflect the difficulties in assessing the station of the fetal head in obese women, resulting in a second stage CS instead of an operative vaginal delivery. Further, the lower rates of operative vaginal delivery in obese women may be explained by the fact that obese women in general have a shorter pushing phase. ${ }^{16,26}$

The clinical implications of the study findings are that the active phase of labor in women with obesity class III and induced labor is prolonged compared to women in other BMI classes. In the future it might be reasonable that partographs are stratified for maternal BMI and to adapt the upper limit of a normal duration of active labor according to maternal BMI. Further, in this national cohort of induced labors, all women who reached the active phase of labor had the same chance for a spontaneous vaginal delivery regardless of maternal BMI. This could be part of information to patients with IOL who might be discouraged if the time from admission until start of active labor is prolonged.

The strengths of this national cohort study are the large number of primiparae women with IOL and early pregnancy BMI, which gave sufficient power to evaluate time in labor according to six BMI classes, and the diversity of a nationwide cohort covering $90 \%$ of all deliveries in Sweden. The detailed data on baseline evaluation of maternal co-morbidity and socioeconomic factors and continuous registration of pregnancy complications enabled us to adjust for possible confounding factors.

General limitations of large register studies are the risk of errors in recorded data and missing values. One example of underreporting variables is the registration of oxytocin for induction/augmentation in the Swedish Pregnancy Register. The use of oxytocin is either automatically transferred from the partogram or manually registered. Although this variable was underreported in the register, there is no reason to suspect that the degree of underreporting varies over the BMI classes. Another variable that was underreported was start of active labor. Among all women with IOL $42 \%$ missed this value. It is possible that the results had been different if all women in the Swedish Pregnancy Register with IOL could have been included in the analyses. However, we only have information on the women 
included in the study-population, with known start of active labor. Nevertheless, it is no reason to believe that the degree of missing start of active labor is related to maternal BMI.

The Swedish Pregnancy Register contains much maternal pregnancy and labor data. Yet, we did not have information on all desirable data. Data on Bishop score at admission, indication and method of induction or indication for CS would have been valuable but was not available. In Sweden, the different methods of induction used, are the same all over the country and the method of induction is chosen based on Bishop score. In general prostaglandins or ballon catheter is chosen if Bishop score is 0-5 and amniotomy and oxytocin infusion if Bishop score is $\geq 6$. Some women require all three methods during IOL. There is probably a variation of which induction methods that are chosen between the different hospitals in Sweden, however there are no reasons to suspect that this variation is related to maternal BMI. There are no national Swedish recommendations for IOL for obese women. In some regions obese women are induced at gestational age $41+0$ instead of $42+0$. Obese women also more often have medical indications for IOL. This could explain why obese women are induced at a lower gestational age than women with normal or low BMI. It is also possible that this could have influenced the results on the time from admission until start of active labor but probably not the duration of the active labor.

Furthermore, we had no information on the exact time that the induction started. Therefore we analysed the time from arrival at the delivery ward to start of active labor. The time "admission to labor ward" has previously been used when analyzing duration of labor in large register-based cohorts ${ }^{25}$.

In Sweden, most women admitted for IOL start induction shortly after arriving at the delivery ward. The time from admission for IOL until start of induction was probably not related to maternal BMI. However, a few obese women may have been observed after admission due to an obstetrical complication before the induction started. This might have biased the results on duration of this phase The fact that we were not able to adjust for the cervical ripeness at admission might also have influenced the results for time from admission to start of active labor, since obese women may have higher risk for unfavorable cervical status and thereby increased risk for longer induction phase. ${ }^{26}$ Due to the worldwide increasing number women undergoing IOL and related resource and space burden at the delivery units, outpatient inductions have been adopted in some countries. Since the phase of cervical ripening is relevant for outpatient as well as inpatient management, our results on time from admission to start of active labor in this national cohort is of value in spite of the related limitations. ${ }^{27,28}$ 
Our definition of start of active labor may limit the generalizability of the present study. In a review article from 2016, Hanley et al. state that there is a lack of international consensus on what degree of cervical dilatation is necessary to indicate that active labor has begun. ${ }^{29}$ An American study has shown that latent labor may last until six centimeters cervical dilatation has occurred. ${ }^{30}$

\section{CONCLUSION}

In conclusion, this study demonstrated that the duration of active labor was associated with maternal BMI in underweight women, who had shorter duration of active labor and in women with $\mathrm{BMI} \geq 40$, who had longer duration of labor compared to women in other BMI classes. Women with $\mathrm{BMI} \geq 40$, who reached the active phase of labor, had the same chance for a spontaneous vaginal delivery as normal weight women but the CS rate was increased. Obese primiparae women who were admitted for IOL spent longer time at the delivery ward from admission to start of active labor compared to normal weight women.

\section{REFERENCES}

1. Stang J, Huffman LG. Position of the Academy of Nutrition and Dietetics: Obesity, Reproduction, and Pregnancy Outcomes. J Acad Nutr Diet. 2016; 116:677-691.

$2 . \quad$ Cedergren MI. Maternal morbid obesity and the risk of adverse pregnancy outcome. Obstet Gynecol. 2004; 103:219-224.

3. Arrowsmith S, Wray S, Quenby S. Maternal obesity and labour complications following induction of labour in prolonged pregnancy. BJOG. 2011; 118:578-588.

4. O'Dwyer V, O'Kelly S, Monaghan B, Rowan A, Farah N, Turner MJ. Maternal obesity and induction of labor. Acta Obstet Gynecol Scand. 2013; 92:1414-1418.

5. Wolfe KB, Rossi RA, Warshak CR. The effect of maternal obesity on the rate of failed induction of labor. Am J Obstet Gynecol. 2011; 205:128 e121-127.

6. Hermesch AC, Allshouse AA, Heyborne KD. Body Mass Index and the Spontaneous Onset of Parturition. Obstet Gynecol. 2016; 128:1033-1038.

7. Roos N, Sahlin L, Ekman-Ordeberg G, Kieler H, Stephansson O. Maternal risk factors for postterm pregnancy and cesarean delivery following labor induction. Acta Obstet Gynecol Scand. 2010; 89:1003-1010.

8. Denison FC, Price J, Graham C, Wild S, Liston WA. Maternal obesity, length of gestation, risk of postdates pregnancy and spontaneous onset of labour at term. BJOG. 2008; 115:720-725.

9. $\quad$ Statistics on Pregnancies, Deliveries and Newborn Infants 2016.

http://www.socialstyrelsen.se/publikationer2018/2018-1-6

: The National Bord of Health and Welfare; 2018.

10. Davey MA, King J. Caesarean section following induction of labour in uncomplicated first births- a population-based cross-sectional analysis of 42,950 births. BMC Pregnancy Childbirth. 2016; 16:92.

11. Thorsell M, Lyrenas S, Andolf E, Kaijser M. Induction of labor and the risk for emergency cesarean section in nulliparous and multiparous women. Acta Obstet Gynecol Scand. 2011; 90:1094-1099. 

risk, labor duration, and cervical dilation rate during labor induction. Obstet Gynecol. 2004; 103:452456.

13. Frederiks F, Lee S, Dekker G. Risk factors for failed induction in nulliparous women. J Matern Fetal Neonatal Med. 2012; 25:2479-2487.

14. Walsh J, Foley M, O'Herlihy C. Dystocia correlates with body mass index in both spontaneous and induced nulliparous labors. J Matern Fetal Neonatal Med. 2011; 24:817-821.

15. Carlhall S, Kallen K, Blomberg M. Maternal body mass index and duration of labor. Eur J Obstet Gynecol Reprod Biol. 2013; 171:49-53.

16. Norman SM, Tuuli MG, Odibo AO, Caughey AB, Roehl KA, Cahill AG. The effects of obesity on the first stage of labor. Obstet Gynecol. 2012; 120:130-135.

17. Pevzner L, Powers BL, Rayburn WF, Rumney P, Wing DA. Effects of maternal obesity on duration and outcomes of prostaglandin cervical ripening and labor induction. Obstet Gynecol. 2009; 114:1315-1321.

18. Lassiter JR, Holliday N, Lewis DF, Mulekar M, Abshire J, Brocato B. Induction of labor with an unfavorable cervix: how does BMI affect success? (double dagger). J Matern Fetal Neonatal Med. 2016; 29:3000-3002.

19. Hirshberg A, Levine LD, Srinivas S. Labor length among overweight and obese women undergoing induction of labor. J Matern Fetal Neonatal Med. 2014; 27:1771-1775.

20. Roloff K, Peng S, Sanchez-Ramos L, Valenzuela GJ. Cumulative oxytocin dose during induction of labor according to maternal body mass index. Int J Gynaecol Obstet. 2015; 131:54-58.

21. Vahratian A, Zhang J, Troendle JF, Savitz DA, Siega-Riz AM. Maternal prepregnancy overweight and obesity and the pattern of labor progression in term nulliparous women. Obstet Gynecol. 2004; 104:943-951.

22. Kominiarek MA, Zhang J, Vanveldhuisen P, Troendle J, Beaver J, Hibbard JU. Contemporary labor patterns: the impact of maternal body mass index. Am J Obstet Gynecol. 2011; 205:244 e241-248.

23. Ellekjaer KL, Bergholt T, Lokkegaard E. Maternal obesity and its effect on labour duration in nulliparous women: a retrospective observational cohort study. BMC Pregnancy Childbirth. 2017; 17:222.

24. Fyfe EM, Anderson NH, North RA, Chan EH, Taylor RS, Dekker GA, et al. Risk of firststage and second-stage cesarean delivery by maternal body mass index among nulliparous women in labor at term. Obstet Gynecol. 2011; 117:1315-1322.

25. Souter V, Painter I, Sitcov K, Caughey AB. Maternal and newborn outcomes with elective induction of labor at term. Am J Obstet Gynecol. 2019; 220:273 e271-273 e211.

26. Zelig CM, Nichols SF, Dolinsky BM, Hecht MW, Napolitano PG. Interaction between maternal obesity and Bishop score in predicting successful induction of labor in term, nulliparous patients. Am J Perinatol. 2013; 30:75-80.

27. Diederen M, Gommers J, Wilkinson C, Turnbull D, Mol B. Safety of the balloon catheter for cervical ripening in outpatient care: complications during the period from insertion to expulsion of a balloon catheter in the process of labour induction: a systematic review. BJOG. 2018; 125:10861095.

28. Barnfield L, Neale E, Reynolds S. Outpatient cervical ripening in a district general hospital: a five-year retrospective cohort study. J Obstet Gynaecol. 2018; 38:301-304.

29. Hanley GE, Munro S, Greyson D, Gross MM, Hundley V, Spiby H, et al. Diagnosing onset of labor: a systematic review of definitions in the research literature. BMC Pregnancy Childbirth. 2016; 16:71.

30. Zhang J, Landy HJ, Branch DW, Burkman R, Haberman S, Gregory KD, et al. Contemporary patterns of spontaneous labor with normal neonatal outcomes. Obstet Gynecol. 2010; 116:1281-1287. 


\section{Legends to figures:}

\section{Figure 1}

Flow chart of the study population.

\section{Figure 2}

Cox regression graphs illustrating time, in hours, in active labor in primiparae women with induced labor in relation to maternal early pregnancy body mass index (BMI). Active labor was defined from onset of regular painful contractions and cervical dilatation $\geq 3 \mathrm{~cm}$ until time of delivery. Time-to-event was studied for all included women, from active labor until delivery, either vaginal delivery (event), or cesarean section (censured data). Adjustments were made for maternal age, birth-weight, gestational weight gain and smoking in early pregnancy. P for difference between BMI groups $<0.001$.

\section{Figure 3}

Cox regression graphs illustrating time, in hours, from admission to labor ward to start of active labor in primiparae women with induced labor in relation to maternal early pregnancy body mass index (BMI). Time-to-event was studied for all included women, from time at admission to labor ward for induction of labor until entering active labor (event). Adjustments were made for birthweight and gestational weight gain. $\mathrm{P}$ for difference between BMI groups $<0.001$. 
All primiparae women, singleton pregnancy, $\geq 37+0$ gestational weeks and delivered between

Jan 12014 and Aug 302017

$n=140452$

\section{Excluded:}

- Spontaneous labor onset $\mathrm{n}=103978$

- Elective cesarean section $n=7956$

- Unknown type of labor start $n=622$ $\leftarrow$

$\downarrow$

Data restricted to women with induction of labor (emergency cesarean section included) $n=27896$

Exclusion criteria:

- Stillbirth $n=134$

- Missing value on $\mathrm{BMI} n=1281$

- Missing value on maternal age $n=8$

- Missing value on start of active labor $n=11761$

Excluded due to faulty data on time from admission to start of active labor $n=186$

- <30 minutes after time at admission

- >96 hours after time at admission

Final study population for analyses of time in active labor $n=15259$

Final study population for analyses of time from admission to start of active labor $n=15073$ 


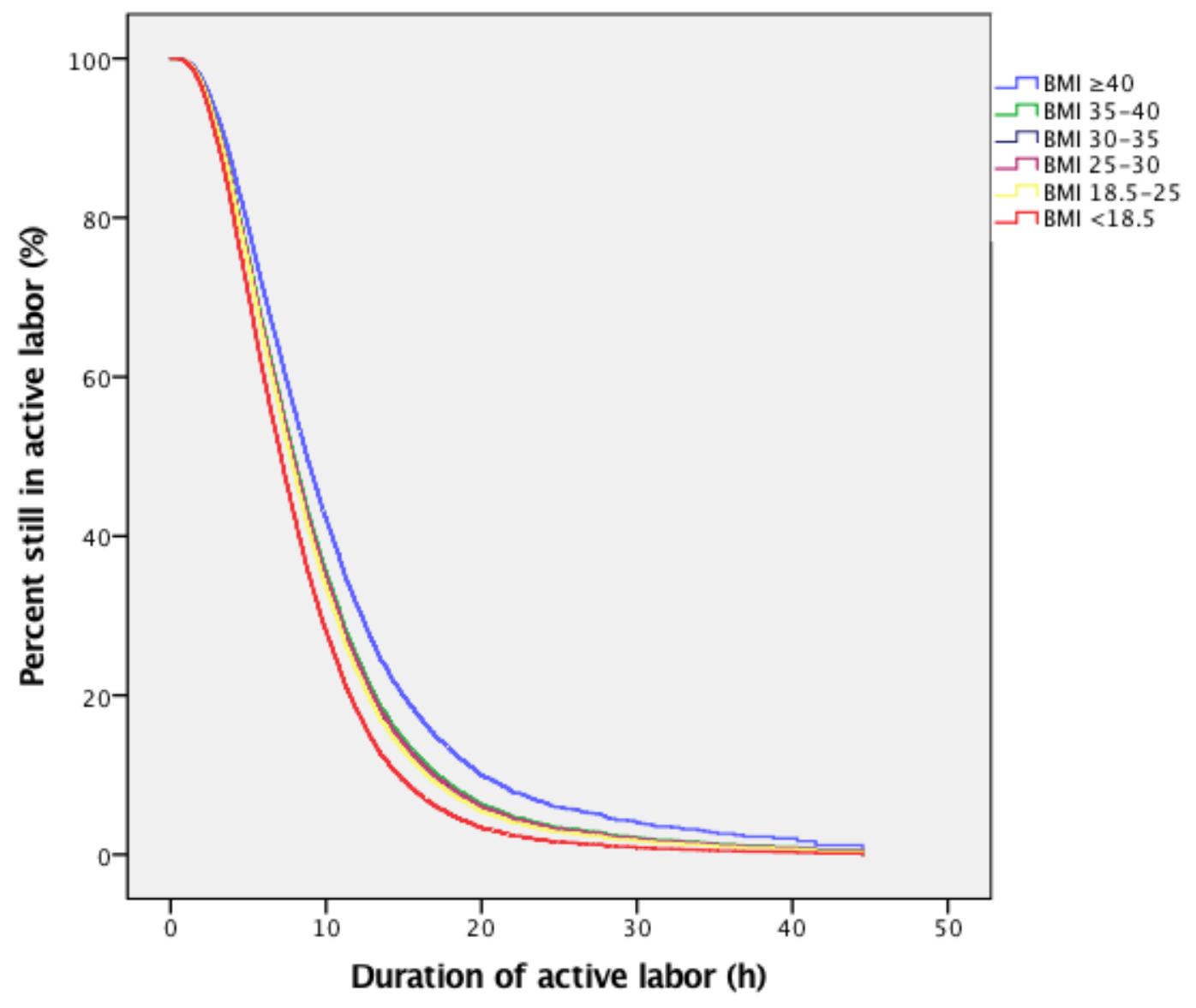




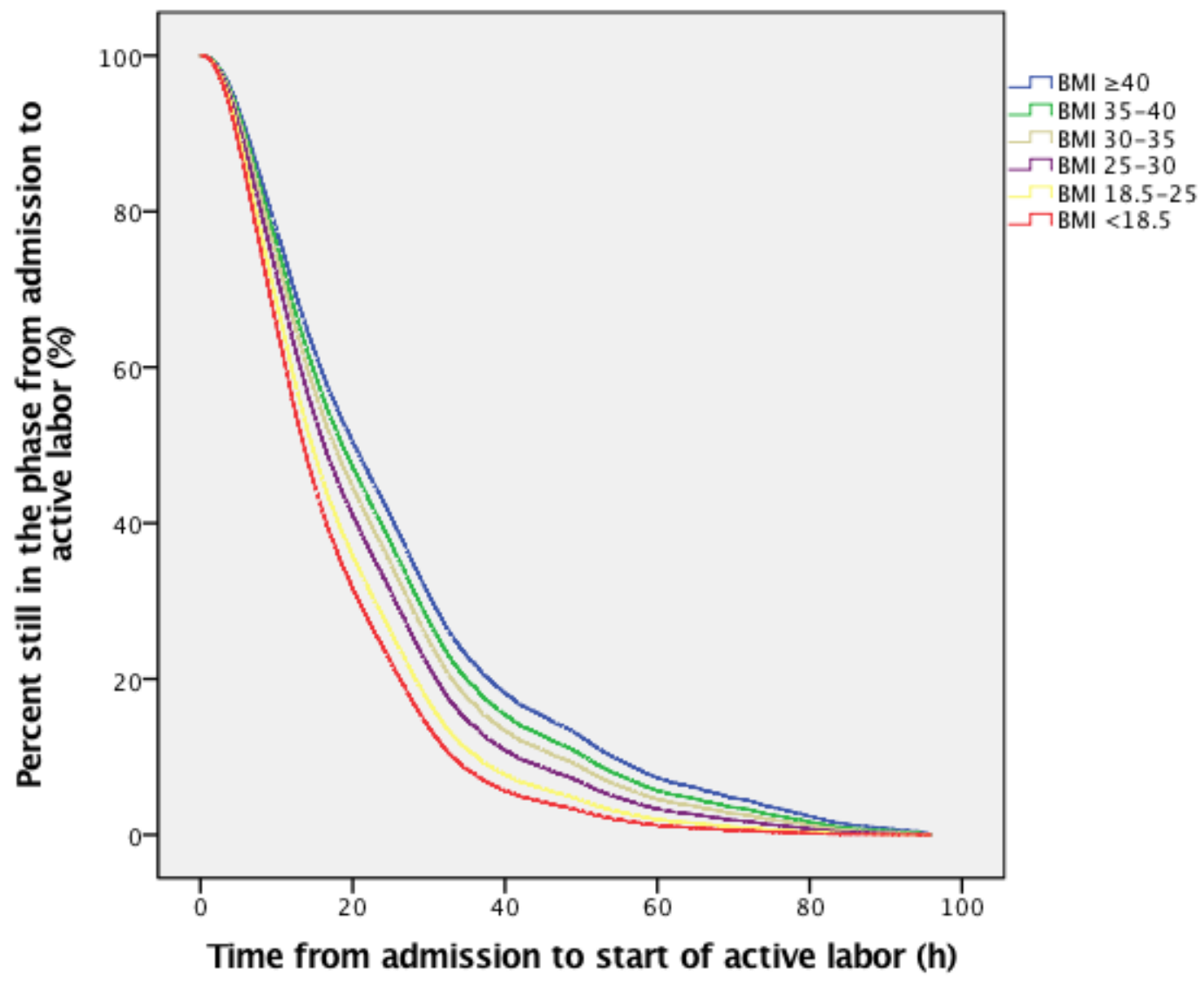


Table 1. Maternal demographics by BMI category, in primiparae term women undergoing induction of labor. Continuous data are presented as mean and $[\mathrm{SD}]$. Categorical data are presented as number and (\%).

\begin{tabular}{|c|c|c|c|c|c|c|c|c|}
\hline $\begin{array}{l}\text { Maternal } \\
\text { demographics }\end{array}$ & $\begin{array}{l}\mathrm{BMI}<18.5 \\
\mathrm{~N}=325 \\
\mathrm{~N}(\%) \\
\end{array}$ & $\begin{array}{l}\text { BMI 18.5-24.9 } \\
\text { N=8,509 } \\
\text { N (\%) }\end{array}$ & $\begin{array}{l}\text { BMI 25-29.9 } \\
\mathrm{N}=4,044 \\
\mathrm{~N}(\%)\end{array}$ & $\begin{array}{l}\text { BMI 30-34.9 } \\
\text { N=1,605 } \\
\text { N (\%) }\end{array}$ & $\begin{array}{l}\text { BMI 35-39.9 } \\
\mathrm{N}=562 \\
\mathrm{~N}(\%)\end{array}$ & $\begin{array}{l}\mathrm{BMI} \geq 40 \\
\mathrm{~N}=\mathbf{2 1 4} \\
\mathrm{N}(\%)\end{array}$ & $\begin{array}{l}\text { Total } \\
\text { N=15,259 } \\
\text { N (\%) }\end{array}$ & $\begin{array}{l}\text { P for homo- } \\
\text { geneity }\end{array}$ \\
\hline Age $<20$ years & $16(4.9)$ & $132(1.6)$ & 77 (1.9) & $26(1.6)$ & $12(2.1)$ & $4(1.9)$ & $267(1.7)$ & $<0.001$ \\
\hline Age $\geq 35$ years & $25(7.7)$ & $1378(16.2)$ & $662(16.4)$ & $24(15.0)$ & $83(14.8)$ & $33(15.4)$ & $2436(15.9)$ & $<0.001$ \\
\hline $\begin{array}{l}\text { Maternal age, } \\
\text { mean years }[S D]\end{array}$ & $27.8[5.0]$ & $30.0[5.1]$ & $29.7[5.3]$ & $29.3[5.4]$ & $29.0[5.5]$ & $28.8[5.1]$ & $29.7[5.2]$ & $<0.001$ \\
\hline $\begin{array}{l}\text { Height, } \\
\text { mean meter [SD] }\end{array}$ & $1.66[6.4]$ & $1.67[6.6]$ & $1.66[6.4]$ & $1.66[6.8]$ & $1.67[6.8]$ & $1.65[9.6]$ & $1.66[6.7]$ & 0.001 \\
\hline $\begin{array}{l}\text { Smoking in first } \\
\text { trimester }\end{array}$ & $27(8.3)$ & $325(3.8)$ & $172(4.3)$ & $120(7.5)$ & $38(6.8)$ & $14(6.5)$ & $696(4.6)$ & $<0.001$ \\
\hline Country of birth & & & & & & & & $<0.001$ \\
\hline Nordic & $167(51.4)$ & $5939(70.0)$ & $2831(70.0)$ & $1146(71.4)$ & $432(76.9)$ & $172(80.4)$ & $10687(70.0)$ & \\
\hline Europe & $39(12.0)$ & $633(7.4)$ & $221(5.5)$ & $97(6.0)$ & $24(4.3)$ & $9(4.3)$ & $1023(6.7)$ & \\
\hline Outside Europe & $75(23.0)$ & $1078(12.7)$ & $557(13.8)$ & $198(12.3)$ & $39(6.9)$ & $13(6.1)$ & $1960(12.8)$ & \\
\hline No information & 44 (13.5) & $859(10.1)$ & $435(10.7)$ & $164(10.2)$ & $67(11.9)$ & $20(9.3)$ & $1589(10.4)$ & \\
\hline Education level & & & & & & & & $<0.001$ \\
\hline$\leq 9$ years & $27(8.3)$ & $397(4.7)$ & $207(5.1)$ & $102(6.4)$ & $38(6.7)$ & $13(6.1)$ & $784(5.1)$ & \\
\hline 9-12 years & $112(34.5)$ & $2274(26.7)$ & $1400(34.6)$ & $653(40.7)$ & $256(45.6)$ & $111(51.9)$ & $4806(31.5)$ & \\
\hline University & $105(32.3)$ & $4311(50.7)$ & $1692(41.8)$ & $560(34.9)$ & $159(28.3)$ & $59(27.6)$ & $6886(45.1)$ & \\
\hline No information & $81(24.9)$ & $1527(17.9)$ & $745(18.4)$ & $290(18.1)$ & $109(19.4)$ & $31(14.5)$ & $2783(18.2)$ & \\
\hline $\begin{array}{l}\text { Hypertension } \\
\text { before pregnancy }\end{array}$ & $3(0.9)$ & $60(0.7)$ & $18(0.4)$ & $9(0.6)$ & $2(0.4)$ & $1(0.5)$ & $93(0.6)$ & 0.501 \\
\hline DM & $4(1.2)$ & $75(0.9)$ & $42(1.0)$ & $5(0.3)$ & $1(0.2)$ & $1(0.5)$ & $128(0.8)$ & 0.044 \\
\hline GDM & $6(1.8)$ & $122(1.4)$ & $46(1.1)$ & $18(1.1)$ & $8(1.4)$ & $0(0)$ & $200(1.3)$ & 0.307 \\
\hline $\mathbf{P E}$ & $15(4.6)$ & $410(4.8)$ & $191(4.7)$ & $67(4.2)$ & $28(5.0)$ & $10(4.7)$ & $721(4.7)$ & 0.931 \\
\hline GWG, mean kg [SD] & $13.4[5.5]$ & $14.6[24.2]$ & $14.4[23.3]$ & $12.7[22.3]$ & 10.8 [7.9] & $8.6[10.2]$ & $14.1[23.0]$ & $<0.001$ \\
\hline Missing GWG (n) & $5(1.5)$ & $113(1.3)$ & $43(1.1)$ & $13(0.8)$ & $1(0.2)$ & $6(2.8)$ & $181(1.2)$ & \\
\hline
\end{tabular}

$\mathrm{DM}=$ pre-gestational diabetes mellitus 
GDM $=$ gestational diabetes mellitus

$\mathrm{GWG}=$ gestational weight gain

$\mathrm{BMI}=$ maternal body mass index in $\mathrm{kg} / \mathrm{m}^{2}$ 
Table 2. Labor characteristics of primiparae term women, undergoing induction of labor, by BMI category. Categorical data are presented as number and (\%). Continuous data are presented as mean and [SD].

\begin{tabular}{|c|c|c|c|c|c|c|c|c|}
\hline $\begin{array}{l}\text { Labor } \\
\text { characteristics }\end{array}$ & $\begin{array}{l}\mathrm{BMI}<18.5 \\
\mathrm{~N}=325 \\
\mathrm{~N}(\%)\end{array}$ & $\begin{array}{l}\text { BMI 18.5-24.9 } \\
\text { N=8,509 } \\
\text { N }(\%)\end{array}$ & $\begin{array}{l}\text { BMI 25-29.9 } \\
\text { N=4,044 } \\
\text { N (\%) }\end{array}$ & $\begin{array}{l}\text { BMI 30-34.9 } \\
\text { N=1,605 } \\
\text { N (\%) }\end{array}$ & $\begin{array}{l}\text { BMI 35-39.9 } \\
\mathrm{N}=562 \\
\mathrm{~N}(\%)\end{array}$ & $\begin{array}{l}\mathrm{BMI} \geq 40 \\
\mathrm{~N}=214 \\
\mathrm{~N}(\%)\end{array}$ & $\begin{array}{l}\text { Total } \\
\text { N=15,259 } \\
\text { N (\%) }\end{array}$ & $\begin{array}{l}\text { P for } \\
\text { homo- } \\
\text { geneity }\end{array}$ \\
\hline GA & & & & & & & & $<0.001$ \\
\hline GA 37.0-40.6 weeks & $174(53.5)$ & $4034(47.7)$ & $1958(48.4)$ & $860(53.6)$ & $320(59.6)$ & $123(57.5)$ & $7468(48.9)$ & \\
\hline GA 41.0-41.6 weeks & $58(17.8)$ & $1487(17.5)$ & $772(19.1)$ & $298(18.6)$ & $112(19.9)$ & $51(23.8)$ & $2778(18.2)$ & \\
\hline GA $\geq 42$ weeks & $93(28.6)$ & $2988(35.1)$ & $1,314(32.5)$ & 447 (27.9) & $139(23.1)$ & $40(18.7)$ & $5012(32.8)$ & \\
\hline $\begin{array}{l}\text { BW mean gram } \\
{[\mathrm{SD}]}\end{array}$ & $3311[553]$ & $3540[518]$ & $3634[544]$ & $3652[553]$ & 3668 [549] & $3671[544]$ & $3578[534]$ & $<0.001$ \\
\hline BW $<2500 \mathrm{~g}$ & $20(6.2)$ & $195(2.3)$ & $74(1.8)$ & $31(1.9)$ & $6(1.1)$ & $2(0.9)$ & $328(2.1)$ & $<0.001$ \\
\hline $\mathrm{BW} \geq 4500 \mathrm{~g}$ & $4(1.2)$ & $259(3.1)$ & $226(5.6)$ & $99(6.2)$ & $38(6.7)$ & $18(8.4)$ & $644(4.2)$ & $<0.001$ \\
\hline EDA & $177(54.5)$ & $5228(61.4)$ & $2496(61.7)$ & $999(62.2)$ & $336(59.8)$ & $136(63.6)$ & $9372(61.4)$ & 0.009 \\
\hline Oxytocin & $179(55.1)$ & $5505(64.7)$ & $2585(63.9)$ & $1022(63.7)$ & $343(61.0)$ & $140(65.4)$ & $9774(64.1)$ & 0.009 \\
\hline Mode of delivery & & & & & & & & $<0.001$ \\
\hline $\begin{array}{l}\text { Spontaneous } \\
\text { vaginal delivery }\end{array}$ & $249(77.1)$ & $6022(70.9)$ & $2743(68.0)$ & $1100(68.7)$ & $377(67.3)$ & $154(72.0)$ & $10645(69.9)$ & \\
\hline $\begin{array}{l}\text { Operative } \\
\text { vaginal delivery }\end{array}$ & $50(15.5)$ & $1321(15.6)$ & $593(14.7)$ & $176(11.0)$ & $69(12.3)$ & $13(6.1)$ & $2222(14.6)$ & \\
\hline Emergency CS & $24(7.4)$ & $1150(13.5)$ & $698(17.3)$ & $326(20.3)$ & $114(20.4)$ & $47(22.0)$ & $2359(15.5)$ & $<0.001 *$ \\
\hline No information & 2 & 16 & 10 & 3 & 2 & 0 & 33 & \\
\hline
\end{tabular}

GA $=$ gestational age

$\mathrm{BW}=$ birth weight

EDA $=$ epidural anesthesia

$\mathrm{CS}=$ cesarean section

$\mathrm{BMI}=$ maternal body mass index in $\mathrm{kg} / \mathrm{m}^{2}$

$\mathrm{SD}=$ standard deviation

$*=\mathrm{p}$ for linear trend 
Table 3. Duration of labor, in hours, in primiparae term women with induction of labor.

\begin{tabular}{|c|c|c|c|c|c|c|c|c|c|c|}
\hline \multirow[t]{3}{*}{$\begin{array}{l}\text { Maternal Body } \\
\text { Mass Index }\left(\mathrm{kg} / \mathrm{m}^{2}\right)\end{array}$} & \multicolumn{5}{|c|}{$\begin{array}{l}\text { Time from admission to start of active phase in } \\
\text { hours. } N=15073\end{array}$} & \multicolumn{5}{|c|}{$\begin{array}{l}\text { Duration of the active phase of labor in } \\
\text { hours. } \mathrm{N}=15259\end{array}$} \\
\hline & \multirow[t]{2}{*}{$\mathrm{N}$} & \multicolumn{3}{|c|}{ Quartiles } & \multirow{2}{*}{$\begin{array}{l}\text { Range } \\
\text { [Min-Max] }\end{array}$} & \multirow[t]{2}{*}{$\mathrm{N}$} & \multicolumn{3}{|c|}{ Quartiles } & \multirow{2}{*}{$\begin{array}{l}\text { Range } \\
\text { [Min-Max] }\end{array}$} \\
\hline & & $25 \%$ & Median & $75 \%$ & & & $25 \%$ & Median & $75 \%$ & \\
\hline$<18.5$ & 322 & 7.7 & 12.9 & 25.0 & {$[1.5-91.7]$} & 325 & 4.0 & 6.1 & 8.9 & {$[0.5-30.5]$} \\
\hline $18.5-24.9$ & 8434 & 8.4 & 14.5 & 25.1 & {$[0.5-95.9]$} & 8509 & 4.7 & 7.4 & 11.0 & {$[0.5-44.5]$} \\
\hline $25-29.9$ & 3993 & 9.2 & 16.3 & 28.2 & {$[0.5-95.6]$} & 4044 & 4.8 & 7.6 & 11.2 & {$[0.5-40.3]$} \\
\hline $30-34.9$ & 1568 & 9.6 & 18.2 & 30.4 & [0.7-94.6] & 1605 & 4.6 & 7.6 & 11.1 & [0.6-46.5] \\
\hline $35-39.9$ & 549 & 10.2 & 21.0 & 31.7 & {$[0.5-80.0]$} & 562 & 4.5 & 7.0 & 11.3 & {$[0.8-30.9]$} \\
\hline$\geq 40$ & 207 & 11.1 & 22.6 & 35.1 & {$[1.0-91.0]$} & 214 & 4.7 & 7.4 & 11.8 & {$[1.3-35.7]$} \\
\hline
\end{tabular}

